\title{
Population-Based Surveillance of Amyotrophic Lateral Sclerosis in New Jersey, 2009-2011
}

\author{
Heather Jordan $^{a, b} \quad$ Jerald Fagliano $^{a} \quad$ Lindsay Rechtman $^{a, b} \quad$ Daniel Lefkowitz $^{a}$ \\ Wendy Kaye ${ }^{\text {b }}$ \\ aEnvironmental and Occupational Health Surveillance Program, New Jersey Department of Health, Trenton, N.J., \\ ${ }^{b}$ McKing Consulting Corporation, Atlanta, Ga., USA
}

\section{Key Words}

Amyotrophic lateral sclerosis · Epidemiology · Incidence .

Prevalence

\begin{abstract}
Background: Limited epidemiological data exist about amyotrophic lateral sclerosis (ALS) in the United States (US). The Agency for Toxic Substances and Disease Registry maintains the National ALS Registry and funded state and metropolitan surveillance projects to obtain reliable, timely information about ALS in defined geographic areas. Methods: Neurologists submitted case reports for ALS patients under their care between January 1, 2009 and December 31, 2011 who were New Jersey residents. A medical record verification form and electromyogram (EMG) report were requested for a sample of case reports. Incidence rates were standardized to the 2000 US Standard Population. Results: The average crude annual incidence rate was 1.87 per 100,000 person-years, the average age-adjusted annual incidence rate was 1.67 per 100,000 person-years, and the point prevalence rate on December 31, 2011 was 4.40 per 100,000 persons. Average annual incidence rates and point prevalence rates were statistically higher for men compared with wom-
\end{abstract}

en; Whites compared with Blacks/African Americans and Asians; and non-Hispanics compared with Hispanics. Conclusions: The project findings contribute new, populationbased, state-specific information to epidemiological data regarding ALS. The findings are generally consistent with previously published surveillance studies conducted in the US and abroad.

(c) 2014 S. Karger AG, Basel

\section{Introduction}

There are limited population-based epidemiologic data on amyotrophic lateral sclerosis (ALS) in the United States (US). Uncertainty about the incidence and prevalence of ALS, as well as limited information regarding its etiology, supports the need for a surveillance system for this disease [1]. The 2008 ALS Registry Act established the National ALS Registry (Registry), which is maintained by the federal Agency for Toxic Substances and Disease Registry (ATSDR). The Registry comprises individuals identified through the use of existing national administrative data sets (Medicare, Medicaid, Veteran's Health Administration, and Veteran's Benefit's Adminis-

\section{KARGER}

E-Mail karger@karger.com

www.karger.com/ned
(C) 2014 S. Karger AG, Basel

0251-5350/14/0431-0049\$39.50/0 
tration) and patients who self-enroll through a secure web portal [2]. To evaluate the completeness of the Registry and to determine the incidence and prevalence of ALS in defined geographic areas, ATSDR developed three state-based (Florida, New Jersey, and Texas) and eight metropolitan area-based (Atlanta, Baltimore, Chicago, Detroit, Las Vegas, Los Angeles, Philadelphia, and San Francisco) surveillance projects [2].

ALS is a rare, progressive, fatal neurological disease affecting both the upper and lower motor neurons. Familial forms of ALS are thought to account for $5-10 \%$ of cases $[3,4]$, and other causes and risk factors are still under investigation, including environmental exposures, occupational exposures, physical activity and trauma, oxidative stress, and genetic factors [4-10]. There is no known cure for ALS.

A definitive clinical test for ALS does not exist, making the disease difficult to diagnose. ALS is diagnosed based on a combination of symptoms, signs and electromyography [11]. The El Escorial criteria use this information to determine possible, probable or definite ALS [11]. It has been demonstrated that using these criteria leads to very high agreement toward the presence of ALS between independent observers when applying the El Escorial criteria to patient charts [12]. The widespread adoption of these criteria by clinicians provides an opportunity for standardized case definition and case eligibility in research studies.

Much of the published literature describing ALS epidemiology is from outside of the US; not all studies provide age-adjusted rates, and case ascertainment methods are varied $[13,14]$. A systematic review of published literature regarding ALS from 1990 to 2004 reported that the median crude prevalence was 4.0 per 100,000 persons, the median crude incidence rate was 1.6 per 100,000 person-years (range $=0.7$ to 2.5 per 100,000 person-years), a weak association with being a man, and a strong association with increased age [13]. A more recent systematic review of the population-based studies published worldwide from 1995 to 2011 reported a higher median crude prevalence of 5.40 per 100,000 persons, a slightly higher median crude incidence rate of 2.08 per 100,000 personyears (range $=0.5$ to 3.6 per 100,000 person-years), and that incidence was the highest among those aged 60-75 [14]. A study of the European Registries confirmed a difference in incidences rates among men and women [15]. Evidence suggests that incidence rates and prevalence are lower among Blacks/African-Americans compared to other races $[16,17]$. Some US-based studies have also noted differences by age, sex, race, and ethnic subgroups, but these results should be interpreted cautiously as sample sizes were small [18-23].

The median duration of time from symptom onset to diagnosis has been reported to range from 9 to 11 months $[24,25]$. The median survival from diagnosis ranges between 16.5 to 23 months $[25,26]$ and most persons with ALS die within three years of diagnosis [26, 27].

The objective of the New Jersey (NJ) ALS Surveillance Project was to gather reliable and timely data to better describe the incidence, prevalence and demographic characteristics of ALS among NJ residents.

\section{Materials and Methods}

\section{Recruitment}

This study was conducted in the state of $\mathrm{NJ}$ with a population of $8,791,894$ persons in 2010 [28]. Neurologists targeted for reporting included all neurologists practicing within the states of NJ and Delaware, two counties in New York, and the county of Philadelphia, $\mathrm{Pa}$., as well as a targeted list of neurologists specializing in the diagnosis/treatment of ALS practicing in Allentown, $\mathrm{Pa}$. and in the New York City region. Pediatric neurologists, neurosurgeons and medical residents were not actively recruited to participate. The neurologists were contacted via letters, phone calls, faxes and face-to-face site visits to determine if they diagnosed or provided care for ALS patients residing in NJ.

\section{Data Collection}

Neurologists who diagnosed or cared for ALS patients were asked to submit a one-page Case Reporting Form for each eligible patient. Eligible patients must have resided in NJ as per the address documented in the patient's chart, had to be under the physician's care at any time between January 1, 2009 and December 31, 2011, and had to fit into one of the El Escorial criteria classification levels [11]. The patients could have been diagnosed before 2009. The Case Reporting Form included questions about patient demographic characteristics, including date of birth, sex, country of birth, race and ethnicity, all of which had predetermined response choices selected by the investigator. The response choice categories for the race question were as follows: 'Asian,' 'Black/African American,' 'White,' 'Unknown,' and 'Other', with an option to specify 'Other.' The response choice categories for the ethnicity question were as follows: 'Hispanic or Latino,' 'Non Hispanic or Latino,' and 'Unknown.' The Case Reporting Form also included questions about month and year of symptom onset, month and year of diagnosis, El Escorial Criteria classification, and healthcare payer type.

Compensation was offered for each completed form. No patients were contacted. This project was approved by the Center for Disease Control and Prevention Institutional Review Board (IRB) and determined to be public health practice not requiring review, by the NJ Department of Health IRB.

To ensure the accuracy of diagnosis, a sample of $10-20 \%$ of reported cases was systematically selected for verification across all state and metropolitan projects. Case selection was weighted to review a greater proportion of cases submitted by small practices 
because of the concern for possible misdiagnosis among providers who rarely diagnose or treat ALS patients. A small practice was defined as one that said they diagnosed or provided care to fewer than five ALS patients during the reporting period. The reporting provider was asked to complete a symptom-oriented Medical Record Verification Form for each selected case, and to attach an electromyogram (EMG) report from which patient identifying information, such as name, social security number, address and date of birth was redacted. The completed Medical Record Verification forms, along with copies of the redacted EMG reports, if available, were forwarded to the project's consulting neurologist for independent assignment of El Escorial criteria classification.

NJ Department of Health death certificate data (2009-2011) and hospital discharge data (2009-2011) were evaluated to identify possible unreported cases of ALS. Death data were searched for International Classification of Diseases-10 code for motor neuron disease (G12.2) because ALS does not have its own specific code [29]. All certificates that explicitly listed a motor neuron disease other than ALS were excluded from follow-up activities. All certifying physicians for the non-reported decedents were contacted and asked if they could identify a neurologist of record for the decedents, and if so, that neurologist was contacted and an attempt was made to collect a case report. Similarly, hospital discharge data were searched for ALS diagnostic code 335.20 [30]. The records for non-reported hospital patients were reviewed and when possible, a neurologist was contacted in an attempt to collect a case report. The attempts to procure case reports via review of death and hospital data are the second wave of data collection.

The 2009-2012 death data were queried to determine if reported cases died from any cause of death. Death certificate information was used to fill-in missing information and to resolve discrepancies between duplicate cases and then the dataset was de-duplicated. For cases reported more than one time, the case record with the most complete information was retained, scanned for missing information and the duplicate case reports were reviewed to fill in any missing information to create a composite, de-duplicated record.

\section{Data Analysis}

To calculate the average annual incidence for 2009, 2010 and 2011 , all cases with a date of diagnosis before 2009 were excluded. To calculate the point prevalence as of December 31, 2011, all cases with a known date of death in 2009, 2010 and 2011 were excluded. Crude and age-specific rates were calculated using the corresponding 2010 US Census population data as the denominator and are presented as cases per 100,000 persons [28]. Age-adjusted rates were standardized to the year 2000 US Standard Population [31].

The time between symptom onset and diagnosis, as well as the survival time for cases known to be deceased as of December 31, 2012 were analyzed for incident cases diagnosed in 2009-2011. Fourteen cases missing a date of diagnosis and/or a date of symptom onset were removed. To calculate the time (in months) between the month and year of symptom onset and the month and year of diagnosis, the total number of months at symptom onset was subtracted from the total number of months at diagnosis (where total months $=\left(\right.$ Year* $\left.^{*} 12\right)+$ Month $)$. To calculate the time (in months) between the month and year of diagnosis and the month and year of death, the total number of months at diagnosis were subtracted from the total number of months at death. Data were analyzed using Microsoft Excel ${ }^{\circledR}$ (2010, Redman, Wash., USA) [32] and SPSS (v19.0, Armonk, N.Y., USA) [33].

New Jersey ALS Surveillance, 2009-2011

\section{Results}

\section{Reporting Providers}

Of the 679 neurologists in the region who were contacted, 168 (25\%) diagnosed or cared for ALS patients in the reporting period; of these, 152 (90\%) reported cases to the project. A physiatrist and generalist also reported cases, for a total of 154 reporting providers. Another 160 (24\%) neurologists did not diagnose or treat ALS patients in the reporting period, but stated they would check on an ALS patient if one presented to them for care. More than $50 \%(351 / 679)$ of the neurologists in the region did not diagnose or treat ALS patients.

\section{Case Ascertainment}

Based on a national ALS prevalence estimate of two cases per 100,000 persons and a survival of two and onehalf years, the team expected to collect reports on about 700 prevalent cases over three years in NJ's population of nearly 8.8 million people $[13,28]$. The team collected 963 case reports from the 154 reporting providers; 199 (21\%) of these were duplicate cases reported by different practices, resulting in a total of 764 unique cases identified through active and follow-up case ascertainment.

Of the 764 unique cases identified, 697 cases were reported before reviewing the death certificate and hospital data. A review of the death certificate data yielded 209 possible ALS decedents and a review of hospitalization records resulted in 81 possible ALS patients who were unmatched to case reports. There were 39 names found in both data sets. Of the 251 possible additional ALS cases, 67 were reported due to follow-up case ascertainment activities.

\section{Case Validation}

A total of 121 Medical Record Verification Forms were requested and 116 (96\%) were received. After a review by the consulting neurologist, all 116 were found to be ALS.

\section{Demographic Distribution of Cases}

Of the 764 collected cases, $84 \%$ were over 50 years of age at diagnosis, $55.1 \%$ were male, $83.2 \%$ were White, and $89.9 \%$ were non-Hispanic (table 1 ).

\section{Incidence}

A total of 493 cases were diagnosed between 2009 and 2011. The crude annual incidence rates for 2009, 2010 , and 2011 were $1.77,1.98$, and 1.85 per 100,000 person-years, respectively, and the average crude annual incidence rate was 1.87 per 100,000 person-years. Age-spe- 
Table 1. Demographic characteristics of reported prevalent ALS cases in New Jersey, January 1, 2009 through December 31, 2011 $(\mathrm{n}=764)$

\begin{tabular}{|c|c|c|}
\hline Demographic characteristic & Count of cases & $\%$ of cases \\
\hline \multicolumn{3}{|l|}{ Age, years } \\
\hline$<30$ & 7 & 0.9 \\
\hline 30-39 & 28 & 3.7 \\
\hline $40-49$ & 87 & 11.4 \\
\hline $50-59$ & 184 & 24.1 \\
\hline $60-69$ & 210 & 27.5 \\
\hline $70-79$ & 172 & 22.5 \\
\hline$\geq 80$ & 71 & 9.3 \\
\hline Unknown & 5 & 0.7 \\
\hline \multicolumn{3}{|l|}{ Sex } \\
\hline Male & 421 & 55.1 \\
\hline Female & 343 & 44.9 \\
\hline \multicolumn{3}{|l|}{ Race } \\
\hline Asian alone & 33 & 4.3 \\
\hline Black alone & 59 & 7.7 \\
\hline White alone & 636 & 83.2 \\
\hline Other $^{\mathrm{a}}$ & 7 & 0.9 \\
\hline Unknown & 29 & 3.8 \\
\hline \multicolumn{3}{|l|}{ Ethnicity } \\
\hline Hispanic & 44 & 5.8 \\
\hline Non-Hispanic & 687 & 89.9 \\
\hline Unknown & 33 & 4.3 \\
\hline Total & 764 & 100.0 \\
\hline
\end{tabular}

Table 2. Age-specific average annual incidence rates for ALS cases diagnosed in three-year period 2009-2011 in New Jersey $(n=493)$

\begin{tabular}{ccll}
\hline Age, years & $\begin{array}{l}\text { Count of } \\
\text { cases }\end{array}$ & $\begin{array}{l}\text { NJ 2010 } \\
\text { population }^{\text {a }}\end{array}$ & $\begin{array}{l}\text { Age-specific } \\
\text { rate }\end{array}$ \\
\hline$\leq 30$ & 4 & $3,385,581$ & 0.04 \\
$30-39$ & 13 & $1,145,041$ & 0.38 \\
$40-49$ & 40 & $1,354,434$ & 0.98 \\
$50-59$ & 114 & $1,240,303$ & 3.06 \\
$60-69$ & 143 & 831,514 & 5.73 \\
$70-79$ & 119 & 476,177 & 8.33 \\
$\geq 80$ & 60 & 358,844 & 5.57 \\
\hline
\end{tabular}

${ }^{a}$ US Census Bureau (2011) [28]. ${ }^{\mathrm{b}}$ Per 100,000 person-years.

cific average annual incidence rates increased with age until age 70-79 (table 2). After adjusting to the 2000 US Standard Population, the total age-adjusted average annual incidence rate was 1.67 per 100,000 person-years. Age-adjusted rates between males and females (1.96 vs.
Table 3. Stratified age-adjusted average annual incidence rates for ALS cases diagnosed in three-year period 2009-2011 in New Jersey $(\mathrm{n}=493)$

\begin{tabular}{|c|c|c|c|c|}
\hline $\begin{array}{l}\text { Demographic } \\
\text { characteristic }\end{array}$ & $\begin{array}{l}\text { Count } \\
\text { of cases }\end{array}$ & $\begin{array}{l}\text { NJ } 2010 \\
\text { population }^{\mathrm{a}}\end{array}$ & $\begin{array}{l}\text { Age } \\
\text { adjusted } \\
\text { rate }^{b}\end{array}$ & $\begin{array}{l}\text { Confidence } \\
\text { interval }^{c}\end{array}$ \\
\hline \multicolumn{5}{|l|}{ Sex } \\
\hline Male & 265 & $4,279,600$ & 1.96 & $1.72-2.20$ \\
\hline Female & 228 & $4,512,294$ & 1.42 & $1.23-1.60$ \\
\hline \multicolumn{5}{|l|}{ Race $^{\mathrm{d}}$} \\
\hline Asian alone & 22 & 725,726 & 1.11 & $0.62-1.60$ \\
\hline Black alone & 31 & $1,204,826$ & 0.88 & $0.57-1.20$ \\
\hline White alone & 413 & $6,029,248$ & 1.80 & $1.62-1.98$ \\
\hline \multicolumn{5}{|l|}{ Ethnicity ${ }^{\mathrm{d}}$} \\
\hline Hispanic & 30 & $1,556,165$ & 0.93 & $0.57-1.29$ \\
\hline Non-Hispanic & 438 & $7,235,729$ & 1.66 & $1.50-1.82$ \\
\hline Total & 493 & $8,791,894$ & 1.67 & $1.52-1.82$ \\
\hline \multicolumn{5}{|c|}{$\begin{array}{l}\text { a US Census Bureau (2011) [28]. }{ }^{\text {b }} \text { Age-adjusted to the year } 2000 \\
\text { US Standard Population [31] and presented per } 100,000 \text { person- } \\
\text { years. }{ }^{c} \text { Rates are statistically significant if the confidence intervals } \\
\text { do not overlap. }{ }^{d} \text { Six cases with a race marked 'Other', } 21 \text { cases with } \\
\text { an 'Unknown' race and } 25 \text { cases with an 'Unknown' ethnicity were } \\
\text { excluded from this table. }\end{array}$} \\
\hline
\end{tabular}

1.42 , respectively), between Whites and Asians (1.80 vs. 1.11 , respectively), between Whites and Blacks (1.80 vs. 0.88 , respectively), and between non-Hispanics and Hispanics (1.66 vs. 0.93 , respectively) were significantly different (table 3).

\section{Prevalence}

Of the 764 cases, 327 died in 2009, 2010 or 2011 and 437 patients were alive on December 31,2011. The crude point prevalence as of December 31, 2011 was 4.97 per 100,000 persons. Three cases were missing age at diagnosis and were removed, leaving 434 cases in the remaining prevalence-related analyses. The age-adjusted point prevalence overall was 4.40 per 100,000 persons (table 4 ). Ageadjusted point prevalence rates between males and females ( 5.21 vs. 3.63 , respectively), between Whites and Blacks (4.62 vs. 2.93, respectively) and between nonHispanics and Hispanics (4.29 vs. 2.61, respectively) were significantly different (table 4 ).

\section{Time from Symptom Onset to Diagnosis}

Of 488 incident cases diagnosed in 2009-2011, the median age at diagnosis for these cases was 64 years (range: 19-90 years); 62 years for men and 66 years for women. The mean duration of time between symptom onset and
52
Neuroepidemiology 2014;43:49-56 DOI: $10.1159 / 000365850$
Jordan/Fagliano/Rechtman/Lefkowitz/ Kaye 
diagnosis was 18 months, the median was 12 months, and $90 \%$ of cases experienced symptoms up to 36 months before diagnosis (range: 0-292 months) (table 5). The length of time between symptom onset and diagnosis was similar by age group, sex, race, and ethnicity.

\section{Time from Diagnosis to Death}

As of December 31, 2012, 53.1\% (259/488) of incident cases diagnosed in 2009-2011 were known to be deceased. The median age at death for these cases was 70 years (range: $35-91$ years); 68 years for men and 72 years for women. The median survival from diagnosis was 29 months. When the analyses were restricted to cases diagnosed in 2009 only, death certificates were retrieved for $64.3 \%(99 / 154)$ of these cases. The median age at death for these cases was 68 years (range: 35-91 years); 67 years for men and 70 years for women. The median survival from diagnosis was 21 months.

\section{Discussion}

Accurate estimates of incidence and prevalence of people affected by ALS in the US are needed by local, state, and federal health agencies, as well as patient services groups, and health care providers [1]. In the US, only a few studies provided epidemiological data for ALS; however, the study sites were small, defined geographic areas, the sample sizes were small, and not all studies relied on neurologists to report cases [18-23]. This report provides the first state-wide data on the incidence, prevalence, demographic characteristics, time from symptom onset to diagnosis, and time from diagnosis to death of ALS, based on a case ascertainment methodology among all neurologists, including neurologists specializing in the diagnosis/treatment of ALS at ALS specialty centers and neurologists in practice at general neurology practices.

There are two major metropolitan areas, New York City and Philadelphia, in close proximity to the NJ state border. Further, there are several ALS specialty centers located in New York, Pennsylvania, and Delaware that are a short distance from the NJ state border. With an understanding that NJ residents frequently seek health care beyond the state border, the outreach and recruitment strategy was broadened to include neurologists in parts of a four-state region. All neurologists in the region were recruited and encouraged to participate to have unbiased case ascertainment. We developed and sustained successful working relationships with reporting providers and their staff, particularly with specialty centers in the region
Table 4. Stratified age-adjusted point prevalence rates as of December 31, 2011 for ALS cases in New Jersey $(n=434)$

\begin{tabular}{|c|c|c|c|c|}
\hline $\begin{array}{l}\text { Demographic } \\
\text { characteristic }\end{array}$ & $\begin{array}{l}\text { Count } \\
\text { of cases }\end{array}$ & $\begin{array}{l}\text { NJ } 2010 \\
\text { population }^{a}\end{array}$ & $\begin{array}{l}\text { Age-adjusted } \\
\text { rate }^{b}\end{array}$ & $\begin{array}{l}\text { Confidence } \\
\text { interval }^{c}\end{array}$ \\
\hline \multicolumn{5}{|l|}{ Sex } \\
\hline Male & 242 & $4,279,600$ & 5.21 & $4.54-5.88$ \\
\hline Female & 192 & $4,512,294$ & 3.63 & $3.11-4.15$ \\
\hline \multicolumn{5}{|l|}{ Race $^{\mathrm{d}}$} \\
\hline Asian alone & 24 & 725,726 & 3.37 & $1.95-4.80$ \\
\hline Black alone & 35 & $1,204,826$ & 2.93 & $1.94-3.92$ \\
\hline White alone & 342 & $6,029,248$ & 4.62 & $4.12-5.12$ \\
\hline \multicolumn{5}{|l|}{ Ethnicity ${ }^{\mathrm{d}}$} \\
\hline Hispanic & 30 & $1,556,165$ & 2.61 & $1.63-3.60$ \\
\hline Non-Hispanic & 372 & $7,235,729$ & 4.29 & $3.85-4.74$ \\
\hline Total & 434 & $8,791,894$ & 4.40 & $3.98-4.82$ \\
\hline
\end{tabular}

${ }^{a}$ US Census Bureau (2011) [29]. ${ }^{b}$ Age-adjusted to the year 2000 US Standard Population [31] and presented by 100,000 persons. ${ }^{c}$ Rates are statistically significant if the confidence intervals do not overlap. ${ }^{\mathrm{d}}$ Five cases with a race marked 'Other', 28 cases with an 'Unknown' race and 32 cases with an 'Unknown' ethnicity were excluded from this table.

Table 5. Time from symptom onset to diagnosis, stratified by age, sex, race, and ethnicity, for reported ALS cases diagnosed in threeyear period 2009-2011 in New Jersey $(n=488)$

\begin{tabular}{|c|c|c|c|}
\hline \multirow{2}{*}{$\begin{array}{l}\text { Demographic } \\
\text { characteristics }\end{array}$} & \multicolumn{3}{|c|}{ Time from symptom onset to diagnosis } \\
\hline & $\begin{array}{l}\text { count } \\
\text { of cases }\end{array}$ & $\begin{array}{l}\text { 50th percentile, } \\
\text { months }\end{array}$ & $\begin{array}{l}\text { 90th percentile, } \\
\text { months }\end{array}$ \\
\hline \multicolumn{4}{|c|}{ Age at diagnosis, in years } \\
\hline$\leq 30$ & 4 & 16 & 27 \\
\hline $30-39$ & 12 & 10 & 20 \\
\hline $40-49$ & 40 & 10 & 29 \\
\hline $50-59$ & 114 & 12 & 40 \\
\hline $60-69$ & 141 & 12 & 29 \\
\hline $70-79$ & 127 & 12 & 35 \\
\hline$\geq 80$ & 50 & 12 & 36 \\
\hline \multicolumn{4}{|l|}{ Sex } \\
\hline Male & 264 & 11 & 36 \\
\hline Female & 224 & 13 & 35 \\
\hline \multicolumn{4}{|l|}{ Race $^{\mathrm{a}}$} \\
\hline Asian alone & 22 & 12 & 24 \\
\hline Black alone & 29 & 13 & 28 \\
\hline White alone & 410 & 12 & 36 \\
\hline \multicolumn{4}{|l|}{ Ethnicity ${ }^{\mathrm{a}}$} \\
\hline Hispanic & 30 & 9 & 26 \\
\hline Non-Hispanic & 433 & 12 & 35 \\
\hline Total $^{\mathrm{b}}$ & 488 & 12 & 36 \\
\hline
\end{tabular}

a Information on 21 cases with a race marked 'Other', 6 cases with an 'Unknown' race; and 25 cases with an 'Unknown' ethnicity is not reported in this table. ${ }^{b}$ Five cases with missing information for symptom onset and diagnosis were removed from the analyses of incident cases. 
that diagnose and care for ALS patients. These relationships were critical for collecting case reports, addressing data quality issues, and obtaining additional case reports for decedents and hospital patients. The patients' willingness to travel and seek care from multiple providers warrants further research into health care seeking behaviors of ALS patients.

Although efforts were made to ensure that neurologists' contact information remained accurate and current, it is possible that some neurologists may have moved into or out of the state, changed practices, or otherwise became unavailable to contact. Neurologists' participation in this project was voluntary because ALS is not a mandatory reportable disease in NJ. We believe our recruitment efforts and compensation offers aided in the high participation rate of neurologists who diagnosed or treated eligible patients.

We were unsuccessful in recruiting a total of seven practices that stated neurologists or staff did diagnose or care for eligible ALS patients in the reporting period, including the two major Veterans Affairs Medical Centers in the region. The team was able to estimate that up to 50 cases went unreported because of their refusal to participate, but it is unclear how many of these cases may have been duplicates.

A total of 433 death certificates from 2009-2011 were identified and 224 (52\%) of these decedents were reported to the project via active data collection. Up to 193 possible ALS cases identified in death and hospital discharge data were not reported. It is unclear how many of these possible cases were actually ALS. Finally, an estimated 3\% of NJ residents die outside of NJ [34]; therefore, it is possible that some residents with ALS died outside NJ and their death certificates have not yet been transferred to NJ. Nevertheless, we are confident that a very large proportion of eligible cases were reported to the project and that very close to $100 \%$ of the death certificates were accounted for in our queries.

Incidence, prevalence, and demographic characteristics of reported ALS cases are similar to previously published findings in the United States and internationally [13-23]. After standardizing to the 2000 US Standard Population, we found significantly higher age-adjusted average annual incidence rates among males compared with females, Whites compared with Asians, Whites compared with Blacks, and non-Hispanics compared with Hispanics. In addition, we found significantly higher age-adjusted point prevalence rates among males compared with females, Whites compared with Blacks, and non-Hispanics compared with Hispanics. Our findings with regard to sex differences are consistent with other published data that used a combination of case ascertainment methodologies such as established registries, case reports from neurologists and hospital billing data $[13,15]$. The differences we found between non-Hispanic and Hispanic point prevalence rates are consistent with the only other published report of this type of ALS data that were collected in the United States (in parts of Texas) [19]. The results we found regarding the lower incidence rate among Blacks/African Americans is also consistent with the literature $[16,17]$. We recommend that future studies examine racial differences among larger samples of the US population.

The median time from symptom onset to diagnosis for incidence cases diagnosed in 2009-2011 was 12 months, which agrees with the findings of the previous research $[15,24,25]$. There were no or small differences between age groups, sexes, race groups and ethnic groups. Upon review of duplicate cases, the reported month and year of symptom onset and diagnosis sometimes varied between reporting providers. When creating composite records for cases reported more than one time, dates were retained from the same case report.

Case reports were collected for persons with ALS under the doctor's care starting in 2009 and those cases could have been diagnosed at any time before 2009. In order for the cases diagnosed before 2009 to appear as decedents in 2009-2012 mortality data, they may have had a longer period of survival compared to incident cases diagnosed in 2009-2001. In fact, the median survival for cases diagnosed before 2009 for which a death certificate was retrieved was 60 months. To avoid biasing our description of survival time toward this longer survival period, we restricted the analyses of time to death to incident cases diagnosed in 2009-2011 and those diagnosed in 2009 only. The median survival time diminished to 29 and 21 months, respectively, and these survival times are aligned with previously published findings [25-27]. However, these findings are subject to censorship, as the follow-up period ended on December 31, 2012, thus allowing only 12 months of follow-up for cases diagnosed in December 2011. A future examination of death certificates beyond 2012 will provide a richer dataset to characterize the survival of this cohort.

\section{Conclusion}

The results of this project provide the first state-wide data on age-adjusted incidence and prevalence of ALS. Conducting time-limited state-based surveillance for a
Jordan/Fagliano/Rechtman/Lefkowitz/ Kaye 
non-reportable chronic condition was challenging, but with proper planning, adhering to data collection methodologies, providing compensation, and executing quality assurance procedures, project objectives were met. Our findings are generally consistent with other ALS surveillance studies in the United States and internationally.

\section{Acknowledgements}

The NJ ALS Surveillance team would like to thank all of the reporting providers and their staff members, for without their support and participation, this project would not have been successful. We also thank the Greater New York and the Greater Philadelphia ALSA Chapters for their assistance with this project. Finally, we would like to thank Dr. Eric Sorenson from the Mayo Clinic and Miro Samawil of the NJ Department of Health for their contribution to the project.

\section{Funding}

This project was funded by McKing Consulting Corporation through a contract funded by the Agency for Toxic Substances and Disease Registry (Contract \#200-2009-32577).

Heather Jordan and Jerald Fagliano had full access to all of the data in the study and take responsibility for the integrity of the data and the accuracy of the data analysis.

\section{Authors' Contributions}

Study Concept and Design: Kaye, Jordan, Fagliano, Lefkowitz, Rechtman; Acquisition of Data: Jordan, Rechtman, Kaye, Lefkowitz, Fagliano; Analysis and Interpretation of Data: Jordan, Fagliano, Rechtman, Lefkowitz; Drafting of the Manuscript: Jordan, Fagliano, Rechtman, Lefkowitz; Statistical Analysis: Jordan, Fagliano; Study Supervision: Fagliano, Kaye, Lefkowitz.

\section{References}

1 Factor-Litvak P, Al-Chalabi A, Ascherio A, Bradley W, Chio A, Garruto R, et al: Current pathways for epidemiological research in amyotrophic lateral sclerosis. Amytroph Lateral Scler Frontotemporal Degener 2013; 14(suppl 1):33-43.

2 Antao VC, Horton DK: The National Amyotrophic Lateral Sclerosis (ALS) Registry. J Environ Health 2012;75:28-30.

-3 Gordon PH: Amyotrophic lateral sclerosis: an update for 2013 clinical features, pathophysiology, management and therapeutic trials. Aging and Dis 2013;4:295310.

-4 Byrne S, Walsh C, Lynch C, Bede P, Elamin $\mathrm{M}$, Kenna $\mathrm{K}$, et al: Rate of familial amyotrophic lateral sclerosis: a systematic review and meta-analysis. J Neurol Neurosurg Psychiatry 2011;82:623-627.

5 Das K, Nag C, Ghosh M: Familial, environmental, and occupational risk factors in development of amyotrophic lateral sclerosis. $\mathrm{N}$ Am J Med Sci 2012;4:350-355.

6 Haley RW: Excess incidence of ALS in young Gulf War veterans. Neurology 2003;61:750756.

7 Fang F, Quinlin P, Ye W, Barber MK, Umbach DM, et al: Workplace exposures and the risk of amyotrophic lateral sclerosis. Environ Health Perspect 2009;117:1387-1392.

$>8$ Beghi E, Logrosino G, Chio A, Hardiman O, Millul A, Mitchell D, et al: Amyotrophic lateral sclerosis, physical exercise, trauma and sports: results of a population-based pilot case-control study. Amyotroph Lateral Scler 2010;11:289-292.

$\checkmark 9$ Fallis BA, Hardiman O: Aggregation of neurodegenerative disease in ALS kindreds. Amyotroph Lateral Scler 2009;10:95-98.
10 Mitsumoto H, Factor-Litvak P, Andrew H, 17 Gundogdu B, Al-Lahham T, Kadlubar F, Goetz R, Andrews L, Rabkin J, et al: ALS Multicenter Cohort Study of Oxidative Stress (ALS COSMOS): study methodology, recruitment, and baseline demographic and disease characteristics. Amyotroph Lateral Scler Frontotemporal Degener 2014; Early Online:1-12.

11 Brooks BR, Miller RG, Swash M, Munsat TL; El Escorial revisited: revised criteria for the diagnosis of amyotrophic lateral sclerosis. World Federation of Neurology Research Group on Motor Neuron Diseases. Amyotroph Lateral Scler Other Motor Neuron Disord 2000;1:293-299.

12 Forbes RB, Colville S, Swingler R: Are the El Escorial and Revised El Escorial criteria for ALS reproducible? A study of inter-observer agreement. Amyotroph Lateral Scler Other Motor Neuron Disord 2001;2:135-138.

13 Hirtz D, Thurman DJ, Gwinn-Hardy K, Mohamed M, Chaudhuri AR, Zalutsky R: How common are the 'common' neurologic disorders? Neurology 2007;68:326-337.

14 Chio A, Logrosino G, Traynor BJ, Collins J, Simeone JC, Goldstein LA, et al: Global epidemiology of amyotrophic lateral sclerosis: a systematic review of the published literature. Neuroepidemiology 2013;41:118130.

15 Logroscino G, Traynor BJ, Hardiman O, Chio A, Couratier P, Mitchell JD, et al: Descriptive epidemiology of amyotrophic lateral sclerosis: new evidence and unsolved issues. J Neurol Neurosurg Psychiatry 2008;79: 6-11.

16 Cronin S, Hardiman O, Traynor BJ: Ethnic variation in the incidence of ALS: a systematic review. Neurology 2007;68:1002-1007.
Spencer H, Rudnicki SA: Racial differences in motor neuron disease. Amyotroph Lateral Scler Frontotemporal Degener 2014;15:114118.

18 Turabelidze G, Zhu B, Schotman M, Malone J, Horowitz S, Weidinger J, et al: An epidemiological investigation of amyotrophic lateral sclerosis in Jefferson County, Missouri, 1998-2002. Neurotoxicology 2008;29:81-86.

19 Wagner L, Archer NP, Williamson DM, Henry JP, Schiffer R, Jackson CE: Prevalence of amyotrophic lateral sclerosis in Texas, 19982003. Tex Med 2012;108:e1.

20 Annegers J, Appel S, Lee J, Perkins P: Incidence and prevalence of amyotrophic lateral sclerosis in Harris County, Texas, 1985-1988. Arch Neurol 1991;48:589-593.

21 Gordon PH, Mehal JM, Holman RC, Rowland LP, Rowland AS, Cheek JE: Incidence of amyotrophic lateral sclerosis among America Indians and Alaskan natives. JAMA Neurol 2013;70:476-480.

-22 McGuire V, Longstreth WT, Koepsell TD, van Belle G: Incidence of amyotrophic lateral sclerosis in three counties in western Washington state. Neurology 1996;47:571-573.

-23 Sorenson EJ, Stalker AP, Kurland LT, et al: Amyotrophic lateral sclerosis in Olmsted County, Minnesota, 1925-1998. Neurology 2002;59:280-282.

24 Cellura E, Spataro R, Taiella A, La Bella V: Factors affecting the diagnostic delay in amyotrophic lateral sclerosis. Clin Neurol Neurosurg 2012;114:550-554.

25 Murphy M, Quinn S, Young J, Parkin P, Taylor B: Increasing incidence of ALS in Canterbury, New Zealand: a 22-year study. Neurology 2008;71:1889-1895. 
26 Tysnes OB, Vollset SE, Larsen JP, Aarli JA: Prognostic factors and survival in amyotrophic lateral sclerosis. Neuroepidemiology 1994;13:226-235.

27 Mitsumoto H, Chad D, Pioro E: Amyotrophic Lateral Sclerosis. Philadelphia: FA Davis Company, 1998.

28 United States Census Bureau/American FactFinder: 'DP1: Profile of General Population and Housing Characteristics: 2010. 2010 Demographic Profile Data. US Census Bureau's American Community Survey Office, 2011. Retrieved from http://factfinder2.census.gov/ bkmk/table/1.0/en/DEC/10_DP/DPDP1/ 0400000US34 (accessed June 2013).
29 World Health Organization: International Statistical Classification of Diseases and Related Health Problems, tenth revision (ICD-10). Geneva: World Health Organization, 1992.

30 Classifications of Diseases, Functioning, and Disability [Internet]: Hyattsville (MD): $\mathrm{Na}$ tional Center for Health Statistics [updated 2010 Jan 4; reviewed 2009 Sep 1]. International Classification of Diseases, Ninth Revision, Clinical Modification (ICD-9-CM) [updated 2010 Sep 21; reviewed 2010 Sep 21; cited 2010 Nov 23]. Retrieved from: http://www.cdc.gov/ nchs/icd/icd9 cm.htm (accessed May 2014).
31 Klein RJ, Schoenborn CA: Age adjustment using the 2000 projected US population. Healthy People 2010 Stat Notes 2001;1-10.

32 Microsoft (2010). Microsoft Excel [computer software]. Redmond, Washington: Microsoft.

33 IBM Corp: Released 2010. IBM SPSS Statistics for Windows, Version 19.0. Armonk, NY: IBM Corp.

34 State of New Jersey Department of Health, New Jersey State Health Assessment Data. Retrieved from: http://www4.state.nj.us/dhssshad/query/DeathQueryTechNotes.html (accessed June 2013). 